\title{
MENTAL CONSTRUCT "MEANDER" AS A UNIVERSAL PROTOTYPICAL SYMBOL IN LANGUAGE AND CULTURE
}

\author{
МЕНТАЛЬНЫЙ КОНСТРУКТ «МЕАНДР» \\ КАК УНИВЕРСАЛЬНЫЙ ПРОТОТИПИЧЕСКИЙ \\ СИМВОЛ В ЯЗЫКЕ И КУЛЬТУРЕ
}

\section{Dimona Amichba ${ }^{1}$}

DOI: https://doi.org/10.30525/978-9934-26-051-3-2

Abstract. In this article, the mental construct "meander" is described from the standpoint of cognitive science and the theory of sign systems, it is considered as a universal prototypical symbol in language and culture. "Meander" is qualified as a deep sign, the mental fields of which are actualized by universal metaphorically structured images. Being an ambivalent "universal" Word, the "meander" in its deep structuring is objectified by mental fields of both positive and negative connotations. Based on the well-known position of Yu. S. Stepanov, according to which language as a construct and it consists of a core, social and mental shells, we were able to not only analyze and describe, but also to show the deep nature and potential capabilities of the prototypical symbol of the "meander". No less important for this work is the thesis that language is "a system capable of generating an infinite number of texts".

"Meander" is characterized by a complex system of symbols, in which each element carries deep meanings and senses. Understanding the complexity of the prototypical symbol system, it should be noted that the study of such a scientific object as a "meander" should not be limited only from the position of linguistic disciplines. At the same time, "Meander" is attributed to both a stereotype and a prototypical symbol, since both concepts are associated with the content side of language and culture, that is, they are understood as mental constructs that correlate with the picture

${ }^{1}$ Candidate of Sciense (Philology), Associate Professor at the Department of Translation and Linguistic Training of Foreigners,

Oles Honchar Dnipro National University, Ukraine 
of the world. The purpose of this article is to describe the multi-component mental construct "meander" from the point of view of its deep structuring. "Meander" as a "stereotype" and a prototypical symbol incorporates the meanings of language and culture, and therefore is understood as a mental construct that adequately reflects the linguistic image of the world. "Stereotypes" and "prototypical symbols", to which we also refer the mental construct "meander", are transmitted by cognitive mechanisms, and, accordingly, are verbalized by one or another sense and meaning. Since the "meander" is a deep abstract prototypical symbol, it is able not only to combine many similar forms of the same object, but also to structure abstract connotative images that are categorized at a deep level. And in this sense, "Meander" is considered by us both as a prototypical symbol, and as a stereotype, and as a pattern, since it is structured according to a model that is often repeated. The results of the analysis showed that the universal, "common human" symbol "meander" is a deeply structured mental construction objectified by meanings and meanings in languages and cultures.

\section{1. Введение}

Проблема универсального «общечеловеческого» Слова, которое является многокомпонентным амбивалентным метафорически структурированным конструктом, вобравшим в себя знаки положительной и отрицательной коннотации, не может утратить своей актуальности. Концепты-конструкты - это, с одной стороны, и метапсихологические, а с другой - и умозрительные образования [1]. Метапсихологические концепты-конструкты имеют под собой общетеоретическую основу, а умозрительные, отвлеченные - позволяют проанализировать компоненты конструкта и рассмотреть вербализованные им понятия в глубинной структурации. Утверждение о том, что концепты-конструкты - это и умозрительные и метапсихологические построения, представляется правильным, так как они объективируются и категоризируются в языке и культуре событиями или фактами. Как в психологии, так и в лингвистике проблема жестко установленных границ концептов-конструктов остаётся все еще дискуссионной. Концепты-конструкты рассматриваются нами как «общечеловеческие», универсальные, которые актуализируются и объективируются метафорически структурированным 
Словом. «Общечеловеческое», универсальное Слово анализируется нами как сложный линейно развёрнутый текст культуры [5, с. 12].

Предложенная научная гипотеза не противоречит известному положению, согласно которому язык - это конструкт в форме шара, состоящий из ядра, социальных и ментальных оболочек. «Снимая одну за другой эти оболочки или слои, мы обнажаем и демонстрируем (глубинную природу и потенциальные возможности языка - А. Д.). Сказанное также справедливо и по отношению к тому, что язык - «это система, способная порождать бесконечное множество текстов» [26, с. 250-254].

Представляет интерес следующая научная гипотеза, предложенная Л. С. Выготским, согласно которой «мысль и слово не связаны между собой изначальной связью, эта связь возникает, изменяется и разрастается в ходе самого развития мысли и слова» $<\ldots .>$. Значение слова оказывается одновременно речевым и интеллектуальным феноменом < .. > Значение слова есть феномен мышления лишь в той мере, в какой мысль связана со словом и воплощена в слове, и обратно: оно есть феномен речи лишь в той мере, в какой речь связана с мыслью и освещена её светом. Оно есть феномен словесной мысли или осмысленного слова, оно есть единство слова и мысли» [11, с. 295-297]. Нет сомнений в том, что «слово есть неисчерпаемый источник новых проблем», сложно не согласиться и с тем, что слово, «лишённое мысли», есть и остаётся «мёртвым» словом. Основное содержание данного тезиса заключается в том, что «слово относится к сознанию, как малый мир к большому, как живая клетка к организму, как атом к космосу. Оно и есть малый мир сознания. Осмысленное слово есть микрокосм человеческого сознания» [11, с. 36].

Общечеловеческая матрица «Слово» выступает носителем культурообразующих форм. Исследуемый научный объект «меандр», являясь многокомпонентным символом, относится к культурообразующим формам, которые способствуют «познанию самого себя» $[17$, с. 11$]$ и своей культуры через призму «чужой». Научная новизна настоящей работы объясняется тем, что впервые описываются и изучаются с точки зрения глубинной семантики ментальные метафорически структурированные образы универсального символа «меандр». Цель представленной статьи - описать многокомпонентный ментальный конструкт «меандр» с точки зрения его глубинной структурации. 
Задачи данного исследования - изучить глубинную структурацию прототипического универсального знака «меандр», проанализировать компоненты структуры, сравнить и сопоставить ментальные образы, объективированные контекстным окружением в языках и культурах.

\section{2. «Меандр» - глубинный символ языка и культуры}

По мнению А. Я Флиера, символ «представляет собой более или менее условное изображение (вербальное, визуальное, звуковое или какое-либо иное) некоего объекта или понятия» [29, с. 95]. Придерживаясь концепции Ф. Соссюра [27], ученый отмечает, что «символ, в первую очередь, знак, соответствующий всем параметрам знака, как его трактуют семиотики» <...>. Но не всякий знак - символ. На наш взгляд, различие между символом и знаком заключается и выражается в их контекстуальной зависимости / независимости <... . Знак, как правило, обозначает одно и то же, независимо от контекста употребления <...>. Символ всегда связан с контекстом его употребления» [29, с. 95]. Отметим, что Ч. Пирс разграничивал феномен знака на знаки-иконы, знаки-индексы и знаки-символы [22], Ю. М. Лотман описывал иконические и условные знаки [20]. «Меандр» можно отнести и к знакам-символам (по терминологии Ч. Пирса), и к условному символу (по терминологии Ю. Лотмана), поскольку для дешифровки такого знака «необходимо знать символическую систему и что именно означает конкретный символ» [29, с. 96].

Проблема соотношения смысла и значения, пронизанная философской идеей их взаимосвязанности и взаимообусловленности, соотносится с проблемой формы и содержания в языке и мышлении. Сложность взаимоотношений указанных категорий в языке и мышлении неизбежно подводит к вопросу, как коррелируются язык и мышление, что следует считать содержанием, а что формой в языке.

«Понятно, что мышление так же, как и язык, объективируется действительностью; язык, являясь формой выражения мышления, структурируется ментальными образами, которые вербализуются в языке. Исходя из этого, можно отметить, что язык и мышление, форма и содержание, значение и смысл характеризуются как внеязыковые категории. Парадокс в том, что эти внеязыковые категории находятся в содержании языка и мышления. Внеязыковые категории, или катего- 
рии сознания, или ментефакты, признаются значениями и смыслами, которые содержат в своих компонентах “содержание структурированного сознания"» [4, с. 36].

Понимая насколько сложен механизм структурации языка и мышления, исследователи справедливо отмечают, что предмет их изучения не должен ограничиваться только лишь лингвистическими дисциплинами. Данное утверждение напрямую относится к анализируемому нами сложному ментефакту, концепту-конструкту «меандр», поскольку в нём сосредоточено содержание «структурированного сознания», которое на глубинном уровне актуализируется универсальными образами как в языке, так и культуре.

Возникают вопросы: можно ли отнести концепт-конструкт «меандр» к прототипическому сложному знаку, или его содержательная сторона может быть охарактеризована как стереотип. Что можно отнести к прототипическому знаку, а что - к стереотипу?

\section{3. «Меандр» как стереотип}

В когнитивной лингвистике и этнолингвистике термин «стереотип» относится к содержательной стороне языка и культуре, то есть понимается как ментальный (мыслительный) конструкт, который корреспондируется с картиной мира.

Понятие «стереотип», как принято считать, в научный оборот ввёл американский писатель, журналист, социолог У. Липпман; в дальнейшем эту теорию расширили и дополнили И. С. Кон, Ю. А. Сорокин и другие исследователи. Стереотип как проблема все еще остается в фокусе внимания и современных ученых, поскольку не утратила своей актуальности. Окружающая человека среда, согласно теории У. Липпмана, во-первых, - «слишком сложное и изменяющееся образование, чтобы можно было познавать ее напрямую» [18, с. 40], во-вторых, необходимо понимать, что картины мира в сознании индивида заслуживают «доверия» не только потому, что находятся «за пределами его досягаемости» $[18$, с. 50], но и потому, что не являются «механическим отображением окружающего их мира» $[18$, с. 51$]$.

Человек имеет о тех или иных вещах представление, которое формируется под влиянием его культурного окружения. Вызывает интерес и тот факт, что стереотипы, по мысли, У. Липпмана, не только пере- 
даются из поколения в поколение и воспринимаются как данность, но и отражают «фрагмент реальности» [18]. Отсюда вытекает мысль, согласно которой восприимчивый, любознательный и внимательный человек стереотипизирует свое восприятие окружающего мира [18]. «Для того чтобы охарактеризовать предмет, необязательно видеть его. Обычно сначала мы даем ему определение, а потом рассматриваем. В огромном шумном многоцветии внешнего мира мы вычленяем то, что уже было определено нашей культурой. Мы воспринимаем предметы через стереотипы нашей культуры» [18, с. 97]. Важно отметить, что «взгляд на внешний мир формировался на основании не подвергавшихся критике картин мира в сознании людей» [18, с. 97].

Язык объективно отражает окружающее культурное пространство человека. Известно, что в обществе складываются стереотипы - как относительно себя, так и относительно поведения и традиций того или иного этноса. Следует признать, что нет однозначного определения и единого мнения относительно феномена «стереотип».

«Языковая картина мира» так же, как и «языковой стереотип», понятия синонимичные: это устойчивое образное сравнение, принятое либо созданное самим народом. Если предположить, что «стереотип» - это некий когнитивный процесс и результат общения, согласно определенным семиотическим моделям, то на этом этапе можно выделить концептуальные пласты соответствующих моделей и норм поведения в форме видовых понятий и стандартов. Причем эти стереотипные понятия будут реализовываться на социально-психическом уровне и уже потом попадать в языковую систему и раскрывать себя там. Так внеязыковая категория и социально-психическая реальность выражают себя на языковом уровне и входят в норму» [23, с. 106-110]. Стереотипом, согласно данной концепции, можно считать относительно устойчивый, обобщающий образ или ряд характеристик этого образа, которые структурируются в сознании человека. Обобщающий образ ценностных доминант можно квалифицировать как стереотип. Указанные характеристика и определения могут коррелировать с содержанием концепта-конструкта «меандр». Изложенное позволяет утверждать, что стереотип - это относительно устойчивый, обобщающий образ или система метафорически структурированных образов, объективированнных в языке и культуре. 
«Меандр», таким образом, как «стереотип» вбирает в себя смыслы языка и культуры, и поэтому понимается как ментальный конструкт, адекватно отражающий языковую картину мира. «Стереотипы» транслируются когнитивными механизмами, и соответственно, вербализуются теми или иными смыслами и значениями. Следует согласиться с утверждением, согласно которому стереотипные понятия реализуются не только «на социально-психическом уровне, но и выражают себя на языковом уровне и входят в норму» [23, с. 110].

\section{4. «Меандр» как прототипический знак}

«Меандр» можно охарактеризовать как прототипический символ, так как представляет собой вероятностный ментальный конструкт; лексические понятия, объективирующие глубинные метафорически структурированные ментальные образы, обладают некоторой вероятностной структурой.

У истоков теории прототипов (от греческого prototypon «прообраз») стоят имена известных исследователей: Л. С. Выготского, Э. Рош, (когнитивная психология), Ф. Лаунсбери (этнолингвистика), Л. Заде (семантика), Б. Берлина, П. Кэйя (когнитивная антропология), Дж. Лакоффа и др. (философия языка). Теория эта основана на философских учениях о феноменологии Э. Гуссерля и М. Мерло-Понти, в которых соединились идея воплощенного характера человеческого опыта и теория значения Л. Витгенштейна. Подробно природа прототипов была описана в известной работе А. Вежбицкой «Прототипы и инварианты» [9, с. 201-213].

«Теория прототипов исходит из установки на изучение естественных психологических процессов формирования категорий, в основе которых лежат доконцептуальные формы повседневного телесного опыта, такие как гештальтное восприятие, моторное движение и воображение (метафора, метонимия, ментальные образы). Внутренняя структура категории, в соответствии с теорией прототипов, имеет асимметричный характер. Ее центром является прототип, вокруг которого группируются, на большем или меньшем расстоянии, другие представители категории. Тот или иной представитель категории выступает в качестве прототипа благодаря наличию у него особых когнитивных свойств: он быстрее распознается, лучше усваивается, чаще употреб- 
ляется. Прототипы представляют собой пучки (кластеры) признаков. Эти признаки интеракциональны, т.е. возникают в результате взаимодействия человека со средой, а не принадлежат самим объектам» [24].

Очевидно, что известный принцип, согласно которому «прототипы не могут «спасти нас» [24] от строгого лексикографического исследования, продолжает оставаться существенным. Вместе с тем следует признать и то, что прототипы позволяют глубже изучить и рассмотреть «лучшие, более глубокие определения, ориентированные на человеческую концептуализацию реальности, которая отражена и воплощена в языке» [24]. Категоризация стереотипов, связанных с глубинными образами «меандра», позволяют раскрыть его природу как символа в языке и культуре. Квалифицируя «меандр» как глубинный абстрактный прототипический символ, можно согласиться и с тем, что он способен объединить в себе множество сходных форм одного и того же объекта; такие объекты присущи и паттерну, фиксирующему шаблонность, схематичность, «типичные свойства» [15, с. 455] объекта.

\section{5. «Меандр» как паттерн}

Исследуемый объект «меандра» как паттерн обнаруживает следующие характеристики: а) амбивалентность, б) выражает значения, в) объективирует глубинный смысл самого знака и компонентов структуры. Паттерн признан элементом «символического уровня» [28, с. 190], он так же, как и прототип, и стереотип, сопоставим с «фразеологическим уровнем в естественном языке» [28, с. 190].

«Паттерн» как термин употребляется для обозначения особенностей многих объектов, чаще всего используется и для описания тех или иных фактов со значениями «преходящий, динамический, вероятностный» [24]. Паттерн рассматривается к тому же и как образец, и как шаблон, и как систематически повторяющийся, устойчивый элемент. Абстрактные образы «меандра» имеют множество сходных форм, которые позволяют описать объект с его преходящими, динамическими, вероятностными характеристиками. Исходя из этого, мы можем говорить о «меандре» так же, как о паттерне или паттернах, которые не только являются фактом культуры и языка, но и характеризуются систематически в своих повторяющихся элементах и устойчивых формах. 
«Новый подход к явлениям категоризации, к понятию как к структуре», согласно Е. С. Кубряковой, содержит «указание на то, какие элементы понятия являются прототипами [16, с. 140]. «Меандр», будучи прототипическим символом, структурирован абстрактными коннотативными образами, которые категоризируются на глубинном уровне. «Меандр» как прототипический символ способен объективироваться по модели, которая часто повторяется. Во всех паттернах этой группы видим часто повторяющийся зигзагообразный орнамент, который символизирует глубинный смысл непрекращающегося движения. Центральной тенденцией, системой передачи глубинного смысла «меандра» как символа являются эксплицитно выраженные орнамент, рисунок, схема. Другими словами, характеризуя сцепление этих ленточных линий, можно говорить о «центальной тенденции» [10, с. 291] орнамента. Визуальный орнамент паттерна позволяет анализировать семиотику «меандра» на эксплицитном и имплицитном уровнях. Поэтому вполне оправданными являются для моделей «меандра» - частотная и центральная «тенденции» [10, с. 291].

Анализируя «особый символический уровень» [28, с. 187] древнего изображения, Б. А. Успенский писал, что «значение символических знаков обусловлено исключительно их семантикой» [28, с. 187]. Отмечая крайнюю формализацию древнего символа, необходимо подчеркнуть и то, что «некоторый знак в целом <...> служит, в свою очередь, обозначением какого-то другого содержания» [28, с. 188]. Глубинная семантика «меандра» помогает сопоставить древний знак с реальностью, другими словами, признать корреляцию древнего символа с действительностью. Несомненно, что паттерн необходимо рассматривать в фокусе семиотического знака, поскольку паттерн и есть ментальный глубинный семиотический знак, конструкт. В связи с этим отметим, что «в силу определенных глубинных психологических установок, связанных с первичными механизмами мифологизации окружающей действительности, любому воспринимаемому объекту, а тем более совокупности объектов может быть приписан характер знака, т.е. передатчика определенной информации, существенной для человека» [25, с. 334]. Бесспорным является и то, что «когда говорят о чём-то, например, о правилах этикета, о мифе или обряде как о знаковой системе, то скорее имеют в виду, что данный объект может быть 
описан примерно теми же средствами, какими современная лингвистика описывает естественный язык. То, что речь идёт не столько о сущности объекта, сколько о способе его описания, лучше всего иллюстрируется тем фактом, что адекватность этих лингвистических методов первичному объекту, т. е. естественному языку или вообще принимается как данность, т. е не подвергается какому-либо анализу, либо же оценивается весьма оптимистически в этом смысле» [25, с. 334.]

Отметим, что не утратила своей значимости и проблема естественных языков как семиотических систем и культурных моделей как семантических. Полемизируя на этот счёт с Э. Бенвенистом, сторонником теории Сепира-Уорфа, Ю. Лотман и Б. Успенский пишут следующее: «При всей целесообразности противопоставления первичной и вторичной моделирующих систем (без такого противопоставления невозможно выделить специфику каждой из них) уместно было бы подчеркнуть, что в реально-историческом функционировании языки и культура неотделимы: невозможно существование языка (в полнозначном понимании этого слова), который не был бы погружен в контекст культуры, и культуры, которая не имела бы в центре себя структуры типа естественного языка. В порядке научной абстракции можно представить себе язык как изолированное явление. Однако в реальном функционировании он влит в более общую систему культуры, составляет с ней сложное целое <...> Культура - генератор структурности, и этим она создаёт вокруг человека социальную сферу, которая, подобна биосфере, делает возможной жизнь, правда не органическую, а общественную» [19, с. 146]. Сложно не согласиться с тезисом, согласно которому «культура вообще может быть представлена как совокупность текстов: однако, с точки зрения исследователя, точнее говорить о культуре как о механизме, создающем совокупность текстов, и о текстах как о реализации культуры» [19, с. 152]. «Меандр» как и любой культурный объект является носителем глубинного семиотического текста.

Модели частотных элементов «меандра» отражают наиболее повторяющиеся признаки, принадлежащие определённым членам категории - это символы «жнизни», «воды», «движения» и т. д. Модель центральной тенденции содержит в себе признаки «семейного сходства» [30, с. 291], разработанные Л. Витгенштейном и Э. Рош. Члены одной 
и той же категории, согласно этому признаку, совместно разделяют основные признаки и совсем не обязательно, чтобы каждый член категории обладал ими [30, с. 291]. Паттерн «меандра», другими словами, в разных культурах несет в себе свойственные данной культуре глубинные смыслы.

\section{6. «Меандр» - глубинный семиотический текст культуры и языка}

Изучение такого символа, как «меандр» с глубинными смыслами и значениями представляет большой исследовательский интерес в силу многоаспектности данной проблемы. «Меандр» (греческое $\mu \alpha i ́ \alpha v \delta \rho o \varsigma)$ принято относить к типу ортогонального орнамента (прямоугольного); этот узор известен в культуре со времен древнекаменного века. «Меандр» также широко использовался и в античном искусстве. Орнамент «меандра» - это ломанная под прямым углом линия, представляет собой спиральные завитки необычной формы. Назначение, смысл и функциональность этого своеобразного узора имеет несколько версий. По одной из них, «меандр» схематически изображает охотничью ловушку - капкан. Такие узоры принято называть петроглифическими, поскольку эти изображения были найдены на камнях. Различают и геоглифические, которые были обнаружены учеными на земле. Исследователи эти изображения относят к известным древнейшим знакам времен первобытных охотников. «Меандр» также считается разновидностью лабиринта; некоторые исследователи отождествляют его со свастикой, которая считается символом света, огня, вечного движения. Обратим внимание на то, что слово «свастика, или хас», по одним данным, состоит из двух санскритских корней - «благо» и «быть, состоять», что, возможно, обозначает «благосостояние», «благополучие»; согласно другим - санскритское слово «су» объективируется значением «солнечная птица и божество времен года Астика» [14]. Третий источник повествует о том, что «свастика, или хас», является солярным символом, одним из самых архаичных знаков, указывающих на видимое движение Солнца вокруг Земли и на деления года на четыре сезона. Этот орнамент, возможно, фиксирует два солнцестояния: летнее и зимнее - годовое движение Солнца, включающее идею четырех сторон света [14]. 
На древнегреческих вазах архаического периода и протокоринфской керамической посуде VII века до н. э встречаются мотивы «меандра» и «свастики». Наложенные друг на друга два меандра получили название «двойной меандр», с метрическим сдвигом на «один шаг» в пересечении дают крест, или свастику. При раскопках археологами столицы древнего Эламского царства Сузы (современный Иран) были найдены глиняные сосуды. На них были изображены спирали, круги, свастики, мотивы волны (знаки воды), зигзаги (знаки молнии и грома) и т. д. [10].

У древних народов Северной и Южной Америки, по данным «Энциклопедии символов» [7, с. 94-95], указанные орнаменты были обнаружены в наскальной живописи. Представляют интерес знаки «воды» у индейцев гопи, и «текучей воды» у ацтеков [там же, с. 94-95]. «Символы воды в простой и запоминающейся стилизации находят ещё в виде наскальных изображений у индейцев гопи. Текучую воду ацтеки изображали как поток из нескольких ручейков, на концах которых рисовали круглые капли и белые домики улиток < .. > древние индейцы, для которых главные ценности в жизни составляли здоровье и пища, хорошо понимали, насколько они зависимы от воды» [там же, с. 94-95].

«Меандр» является, по всей видимости, также и одним из древнейших символов стихий, и по сходству с наименованием позднее его стали связывать с извилистым руслом реки Меандр, который сегодня частично сохранил своё название - Большой Мендерес в Малой Азии, или Анатолии. Отметим, что Анатолия, которая переводится с греческого как «восход солнца», граничит с Кавказом. Этот факт очень существенен для настоящей работы.

Важно подчеркнуть, что эти географические данные известны со времен античного историка и географа Римской Греции Страбона, который в I веке, описывая особенности этой реки в Малой Азии, обращал внимание на извилистое течение, называемое меандрами. Римский философ, стоик, поэт и государственный деятель Сенека в своё время писал о том, что река Меандр является источником вдохновения и как «предмет упражнений и игры для всех поэтов, вьётся частыми излучинами, близко подступает к собственному руслу и опять поворачивает, не успевши влиться в себя самоё» (Сенека. Нравственные письма к Луцилию CIV)» [21]. 
Все ещё остаётся не решенной проблемой происхождение слова «меандр», вызывают, несомненно, интерес и вероятностные глубинные смыслы этого ментального конструкта, и в этом мы видим ценность его описания и анализа. Дискуссионным является и вопрос: то ли название реки произошло от наименования орнамента, то ли орнамент назвали по ассоциации с рекой. Подчеркнём, что орнамент, похожий на греческий «меандр» (как и мотив «свастики»), известен по памятникам древнего искусства Китая и Японии. Учёными были найдены предметы: керамические изделия, бронзовые сосуды периодов Шан и Чжоу, изделия из костей эпохи неолита (примерно 2-1 тыс. до н. э), на которых были изображены указанные узоры [10, с. 397-398]. Известно, что в древнем Китае мотив «меандра» называли лэй вэнь «узоры грома»; в Японии подобный символ - рюсуймон «бегущая вода». Зигзагообразный, или ленточный орнамент, встречается в памятниках культуры Древней Америки. Непрерывность такого мотива идеально выражает непрерывность движения, течения времени и человеческой жизни.

Из изложенного выше можно заключить, что «Меандр» является амбивалентным знаком, изображен на многих предметах материальной культуры. Необычен и сам узор «меандра». Полосы, ленты, контуры «меандра», обращённые слева направо, символизируют «свет» и «добро», а справа налево - «зло».

Одним из символов христианства, как известно, является Люцифер, до свершения зла этот падший ангел считался «самым прекрасным из всех ангелов, созданных Господом» [7, с. 196]. Люцифер - дословно «тот, кто несёт свет»; по христианским представлениям, «если зло всё же существует в мире, и оно не от Бога, то зло должно иметь иное происхождение, а именно - от дьявола. Опыт средневекового человека - голод, лишения, религиозные войны, чума, социальные потрясения - слишком явно свидетельствовал о наличии боли и страданий, борьбы и ненависти. Надо было дать имя этим несчастьям, и оно было дано - дело рук сатаны» [7, с. 197]. Символ, объективированный отрицательной коннотацией, обнаруживается и в «сатанинской печати» [7, с. 198], который так же содержит элементы «меандра». Интересный факт: включение в «меандр» свастики, по данным эзотерических материалов, означает присутствие в естественных жизненных процессах дополнительного фактора сверхъестественной благодати, которая 
в итоге становится доминирующим, организующим узлом каждого отрезка пути [10]. В индийской культуре определяется этот символ словом «nandavartaya» (нандавартайя), что обозначает «свивание» или «круг счастья». «Меандр» использовали в этрусской, древнегреческой, древнеримской, византийской и романской архитектурах. Для древнеримской архитектуры также характерен двойной меандр, который в пересечениях образует «свастику». Такую «свастику» украшал горизонтальный пояс наружных стен Алтаря мира. Этот жертвенник был построен в честь римской богини мира и благоденствия Пакс, а также победы императора Августа и его триумфальному возвращению из Испании и Галлии, добившегося мира, благополучия и счастливой жизни в этом регионе, данный факт датируется историками 13-ым годом до н. э. [14].

У монголоязычных народов «меандр», или «алхан хээ», своей внутренней формой восходит к слову алха, которое в переводе с бурятского и монгольского языков обозначает «молоток»; такой узор получил название «молоточный». Молоточный орнамент объективируется глубинными смыслами вечного движения, материально связан с древними орудиями труда; этот символ встречается на предметах материальной культуры (вещах, мебели, частях декора, коврах, вышивке, посуде, упряжи, музыкальных инструментах) [14]. Очевидно, что алха «молоток» у монголоязычных народов может коррелировать с аиха «железо» у абхазов. Основанием для такого сравнения и сопоставления являются факты, описанные в специальной литературе [3; 6; 7]. Ритуальные предметы кузнечного ремесла - ажьахэа «молот» [2, с. 386], апсынгьыры «наковальня» [7, с. 201], арытэа «щипцы, клещи, плоскогубцы» [2, с. 155] - сакральные предметы материальной культуры абхазов, символизируют жизнь, точнее, зарождение жизни, ценности семьи и рода. Композит «ажьахэра», по всей видимости, основан на метафорическом переносе и связан с образом божества кузницы ажьахара [2, с. 386]. Как пишет В. Л. Бигуаа, культ железа многими народами, в том числе и абхазами, воспринимался «как небесный дар, как дар божий» [7, с. 223].

Поклонение кузнице и предметам кузнечного ремесла В. Л. Бигуаа объясняет тем, что «практика знакомства с железом имела место во всех древних цивилизациях. Возраст раннего железного изделия метеоритного происхождения, найденного в северной части Месопотамии, 
насчитывает семь тысяч лет. Известно еще, что и в соседних цивилизациях метеоритное железо распространилось очень рано и получило исключительное значение в религиозной жизни народов, проживавших в них. Из него они делали амулеты, культовые талисманы, несколько позже и оружия» [7, с. 223].

С. А. Григорьев пишет о значимости у многих народов мира изделий из железа. Предметы культуры, найденные в Саммаре, в Северной Месопотамии, датируются исследователями 5000 г. до н. э. Уже к IV-II тыс. до н. э. и в эпоху поздней бронзы, всё ещё оставаясь редкостью, количество этих изделий, в сравнении с бронзовыми, возрастает. Ценное железо, из которого изготавливали украшения и культовые предметы, по стоимости превосходило серебряные изделия. Хеттские источники донесли до нас сведения о железном царском троне. Кинжал с железным лезвием был обнаружен в гробнице Тутанхамона. Из переписки хеттского царя Хаттусилиса III с Шалманасаром V известно, что первый правитель послал в подарок второму - железный клинок. В этой же статье С. А. Григорьев, ссылаясь на научную работу В. Г. Ардзынба [6], пишет о том, что «существовала также хаттская, а затем и хеттская традиция сакрализации железа и его производства. Эта традиция была впоследствии воспринята северо-кавказскими народами» [13, с. 73].

Нет сомнения в том, что на предметах материальной культуры изображались символы, имеющие большое значение для того или иного народа, более того, на многих из них высекались фигуры и орнаменты, схожие с «меандром». Как мы уже отметили, памятники материальной культуры, на которых изображён «меандр», были найдены не только в указанных выше древних государствах, но и на Кавказе, в Крыму, причём узоры, напоминающие «меандр», сохранились не только на предметах быта, но и одежде. Кавказские тамги, в частности абхазо-адыгские тамги фамильных родов, содержат элементы, напоминающие двойной «меандр», ленточные узоры. Все эти формы символизируют глубинные ценностные смыслы родов, которые всё еще остаются мало изученными.

Можем предположить также, что «меандр» является символом «срединной реки», или «реки жизни». Несомненным является тот факт, что «меандр» как паттерн принадлежит не только греческой культуре. Корни его уходят в глубь веков. Более того, внутренняя форма «меандра» может быть связана со значением «река», «вода», «направление реки». 
Сказанное не противоречит тому, что было изложено выше, потому что, как известно, река Меандр, по сведениям древних путешественников и историков, находилась на территории Передней Азии. Передняя Азия охватывает территорию Кавказа, отсюда вывод: возможно, это одна из рек, протекающих по этой территории. Вопрос этот пока ещё остаётся открытым, поскольку неизвестно современное название реки. Можно только предположить, что в языках сохранились реликтовые формы, связанные либо с внутренней формой самого названия «меандр», либо внутренней формой названий фамильных имён или топонимов.

Представляет в связи с изложенным интерес абхазское фамильное имя Асэзба, которое дословно можно перевести как «два+река+ патроним -БА, двуречье, или междуречье. Другой, не менее интересный факт: известная река в Дагестане Самур (ЧІвехер вацl) называется ещё и словом кьулан ваці [12], которое дословно переводится как «серединная река». Сравним с названим абхазской деревни Азсэыбжьа (дословно вода + два + делить - разделённая водой), что переводится описательно так же, как срединная река. Возникает вопрос: связано ли это название реки у народов, проживающих возле, около, недалеко от нее, с их представленим о пространственной ориентации. И как это воплощается в языках.

Нет сомнения в том, что конструкт «меандр» вобрал в себя глубинный смысл, который в языке и культуре народов Кавказа объективируется еще и значеним «что-то разделённое на что-то, разделённое между или середина чего-то».

Не менее интересно и другое название «свастики» - «хас». Считаем, что, например, идиома «а-хаас» с основой, в которой сосредоточен рассматриваемый формант хас / хаас в абхазском языке, употребляется с аффиксом общности $\boldsymbol{A} \boldsymbol{A}$ как выражение крайней степени удивления или же огорчения и является реликтовой формой древнего представления о высшей силе, к которой в критические ситуации взывают к помощи. Полагаем, что современный абхазский язык утратил первоначальное значение этой идиомы, значение этого слова деэтимологизировалось. Отметим также, что, по данным толкового словаря, вышедшего под редакцией В. А. Касландзия, это слово рассматривается как «проститутка, уличная девка» [2, с. 265]. Можем предположить, что этим словом называли древнее божество, связанное с водой, 
рекой и т. д. Возникает ещё один сложный вопрос: это слово заимствованное или оно имеет свои глубинные местные корни. Нелёгкий, интересный вопрос, который пока еще остаётся без ответа.

Очевидно, что образ срединной реки или, возможно, реки жизни, в сознании людей был связан с чем-то сакральным, важным, насущным. Понятно, что соседство человека и воды, реки было существенным фактом, прежде всего, для самого человека. Если говорить о реке, то роль её для жизнеобеспечения человека трудно переоценить. Люди, живущие возле, около, недалеко от воды, реки, могли сохранить в своих языках слова и выражения, вербализующие внутреннюю форму, с одной стороны, а с другой - указание на то, где находилась, в какой земле эта срединная река - на Кавказе или в древней Месопотамии, или Греции.

Бесспорным является пока лишь один факт: этот паттерн, стереотип, прототипический образ носит универсальный характер. И вопрос о том, какой народ заимствовал и у кого этот образ пока ещё остается дискуссионным и открытым. Можем ли мы допустить, что этот паттерн не восходит только к древнегреческой культуре, и что, возможно, он заимствован у других народов. Этот древний символ структурирован глубинными значениями и смыслами, и это очевидный факт. Нет сомнения также в том, что этот паттерн в языке и культуре является «общечеловеческим» символом, и что он не принадлежит одной какой-то конкретной культуре.

Так, например, в языке лезгин встречаются слова и выражения с указанным выше смыслом. Форма къул «середина» с тем же значением и синонимичное юкъв (къуьч) «за пазухой», в смысле «в середине чего-то», къюлан ттар «позвоночник», «хребет», которое буквально переводится как «середина дерева» [12].Топонимический объект къулан хуьр «срединное село» [12] = ср.: абхазский топоним Азсэбжьа, которое дословно переводится как «два+река+ между - разделённая дважды рекой или место, разделенное рекой».

Остаётся также дискуссионным вопрос: имеет ли прямое или косвенное отношение «солнечное озеро» к глубинным образам «меандра». Напомним, что «солнечное озеро» упоминается Гомером, но учёные не знают, связано ли оно с Каспийским морем. Вс. Иванов допускает, что это озеро могло находиться к востоку от Средиземного моря. Свою точку зрения исследователь подкрепляет гипотезой, согласно которой, 
возможно, миграция индоевропейских племен происходила с востока на запад. Уже сегодня многочисленные археологические данные подтверждают эту научную гипотезу.

\section{7. Выводы}

Подводя итог, можно с уверенностью утверждать, что «меандр» является универсальным глубинно структурированным ментальным конструктом, который объективирует смыслы и значения в языках и культуpax. Нет сомнения в том, что прототипический, или стереотипический, символ «меандр» тесно переплетается с культурой и языками Кавказа.

Перспектива для дальнейшего изучения данной проблемы. Все высказанные выше суждения и анализ изученного материала позволяют продолжить дальнейшее изучение глубинных смыслов паттерна «меандр».

\section{Список литературы:}

1. Абушенко В. Л., Швырёв В. С. (2018). Конструкт. URL: http://gtmarket.ru/ concepts/6889. Последняя редакция: 03.01.2018.

2. Абхазско-русский словарь: в 2 т. (2005) / Сост. В. А. Касландзия. Москва : ОЛМА-ПРЕСС; 1424.

3. Аджинджал И. А. (1969). Из этнографии Абхазии. Сухуми: 583.

4. Амічба Д. П. (2016). Универсальное, общечеловеческое «Слово» : форма и содержание, смыслизначение, образисимвол.Лінгвістика.Лінгвокультурологія: 3б. наук. пр. : Іншомовний дискурс: складники, проблеми та навчання / за заг. ред. О. І. Панченко, Ю. О. Шепель. Дніпропетровськ : Акцент ПП, Т. 9: 36-46.

5. Амичба Д. П. (2020). Концепт-конструкт «конъюнктура» в ментальних «общечеловеческих» образах: этимологический этюд. Лінгвістика. Лінгвокультурологія : картина світу у життєдіяльності людини / За ред. акад. НАНВО України, проф. Ю. О. Шепеля. Дніпро : Акцент ПП. Т. 16: 10-24.

6. Ардзинба В. Г. (1988). К истории культа железа и кузнечного ремесла (почитание кузницы у абхазов). Древний Восток: этнокультурныле связи. Москва: 263-306.

7. Бауер В. (2000). Энциклопедия символов. Москва: Крон-Пресс: 504.

8. Бигуаа В. Л. (2018). Ритуальный мир традиционной религии абхазов : монография. Москва : МАКС Пресс: 336.

9. Вежбицкая А. (1996). Прототипы и инварианты. Язык. Культура. Познание. Москва: 201-213. URL: http://www.philology.ru/linguistics1/wierzbicka-96a.htm

10. Власов В. Г. (2006). Меандр. Новый энциклопедический словарь изобразительного искусства. В 10 т. Санкт-Петербург: Азбука-Классика. T. V: 397-398.

11. Выготский Л. С. (1982). ПСС в 6 Т. Т. 2: Проблемы общей психологии. Москва: Педагогика: 504. 
12. Гаджиев М. М. (1950). Русско-лезгинский словарь: 35000 слов / под ред. Г. А. Аликберова. Изд-во Дагестанский филиал Академии наук Союза CCP. Махачкала, 1950. URL: http://lezgiyar.ru/load/smotret_on_lajn_roliki/ russko_lezginskij_slovar_m_m_gadzhieva/4-1-0-19

13. Григорьев С. А. (2000). Древнее железо Передней Азии и некоторые проблемы археологии Волго-Уралья. Известия Челябинского научного иентра. Вып. 1. Челябинск: 73-78.

14. Двенадцать (12) орнаментов. Анализ монгольских орнаментов. URL: https://nadval.livejournal.com/39056.html

15. Ивин А. А. (2004). «Философия. Энциклопедический словарь». Москва : Гардарики: 1072.

16. Кубрякова Е. С. (1997). Краткий словарь когнитивных терминов. Москва : Филол. ф-т МГУ им. М. В. Ломоносова: 245.

17. Леонтьева В. Н. (2003). Культуротворческий процесс: основания и начала. Харьков : Консум: 216.

18. Липпман У. (2004). Общественное мнение / Пер. с англ. Т. В. Барчунова, под ред. К. А Левинсон, К. В. Петренко. Москва : Институт Фонда «Общественное мнение»: 384.

19. Лотман Ю., Успенский Б. (1971). О семиотическом механизме культуры. Труды по знаковым системам 5. Учёные записки. Тартуский государственный университет / под ред. Ю. Лотмана. Тарту. Вып. 284: 144-176.

20. Лотман Ю. М. (1973). Семиотика кино и проблемы киноэстетики. Таллин : Ээсти Раамат: 92.

21. Луцилий Анней Синека (1977). Нравственные письма к Луцилию. Письмо CIV / отв. ред. М. Л. Гаспаров, перевод, примечание, подготовка издания С. А. Ошеровой, Москва : «Наука». URL: http://ancientrome.ru/ antlitr/t.htm? $\mathrm{a}=1346570104$

22. Пирс Ч. С. (2000). Избранные философские произведения. Москва : Логос: 448.

23. Попко Л. П. (2007). Неологизация в языке как трансляция культурно-лингвистической ментальности: [монография]. ГАРККиИ: 360.

24. Прототип. URL: http://terme.ru/termin/prototip.html

25. Ревзин И. И. (1971). Субъективная позиция исследователя в семиотике. Труды по знаковым системам 5. Учёные записки. Тартуский государственный университет / под ред. Ю. Лотмана. Тарту. Вып. 284: 334-344.

26. Степанов Ю. С. (2004). Константы: словарь русской культуры. Москва : Эксмо: 672.

27. Соссюр Ф. де (2004). Курс общей лингвистики. Москва : Едиториал УPCC: 256.

28. Успенский Б. А. (1971). О семиотике иконы. Труды по знаковым системам 5. Учёные записки. Тартуский государственный университет / под ред. Ю. Лотмана. Тарту. Вып. 284: 144-166.

29. Флиер А. Я. (2016). Символ в культуре: генезис - функции - значимость. Обсерватория культуры. Т. 1. № 1: 94-99. URL: https://observatoria.rsl.ru/ jour/article/viewFile/310/15 
30. Naime J. S. (2009). Psychology. USA, Belmont: Wadsworth: 565.

\section{References:}

1. Abushenko V. L., Shvyrev V. S. (2018). Construct [Construct]. URL: http://gtmarket.ru/concepts/6889 Poslednyaya redaktsiya: 03.01.2018.

2. Abkhazsko-russkiy slovar (2005) [Abkhaz-Russian dictionary]: v 2 t. [Sost. V. A. Kaslandziya]. Moscow: OLMA-PRESS: 1424. (in Russian)

3. Adzhindzhal I. A. (1969). Iz etnografii Abkhazii [From the ethnography of Abkhazia]. Sukhumi: 583. (in Russian)

4. Amíchba D. P. (2016). Universal'noye, obshchechelovecheskoye «Slovo»: forma i soderzhaniye, smysl i znacheniye, obraz i simvol [Universal "Word": form and content, meaning, image and symbol]. Linguistics. Linhvokulturolohiya: Zb. nauk. pr.: Inshomovnyy dyskurs: skladnyky, problemy ta navchannya. Dnipropetrovs'k: Aktsent PP. T. 9: 36-46.

5. Amichba D. P. (2020). Kontsept-konstrukt «konyunktura» v mental'nikh «obshchechelovecheskikh» obrazakh: etimologicheskiy yetyud [Concept construct "conjuncture" in mental "universal" images: an etymological study]. Linguistics. Linhvokul'turolohiya: kartyna svitu u zhyttedyal'nosti lyudyny / Za red. akad. NANVO Ukrayiny, prof. Yu. O. Shepelya. Dnipro: Aktsent PP. T. 16: 10-24.

6. Ardzinba V. G. (1988). K istorii kul'ta zheleza i kuznechnogo remesla (pochitaniye kuznitsy u abkhazov) [To the history of the cult of iron and blacksmith's craft (reverence for the forge among the Abkhaz)]. Drevniy Vostok: etnokul'turnyye svyazi. Moscow: 263-306.

7. Bauyer V. (2000). Entsiklopediya simvolov [Encyclopedia of symbols]. Moscow: Kron-Press: 504. (in Russian)

8. Biguaa V. L. (2018). Ritual'nyy mir traditsionnoy religii abkhazov [The ritual world of the traditional religion of the Abkhaz]: Moscow: MAKS Press: 336. (in Russian)

9. Vezhbitskaya A. (1996). Prototipy i invarianty [Prototypes and invariants]. Yazyk. Kul'tura. Poznaniye. Moscow: 201-213. URL: http://www.philology.ru/ linguistics1/wierzbicka-96a.htm

10. Vlasov V. G. (2006). Meandr. Novyy entsiklopedicheskiy slovar' izobrazitel'nogo iskusstva [New Encyclopedic Dictionary of Fine Arts]. V 10 t. SPb.: Azbuka-Klassika. T. V.: 397-398.

11. Vygotskiy L. S. (1982). PSS v 6 T. T. 2: Problemy obshchey psikhologii. [Problems of general psychology]. Moscow: Pedagogika: 504. (in Russian)

12. Gadzhiyev M. M. (1950). Russko-lezginskiy slovar'[Russian-Lezghin dictionary]: 35000 slov / pod red. G. A. Alikberova. Izd-vo Dagestanskiy filial Akademii nauk Soyuza SSR. Makhachkala. URL: http://lezgiyar.ru/load/smotreton_lajn_roliki/russko_lezginskij_slovar_m_m_gadzhieva/4-1-0-19

13. Grigor'yev S. A. (2000). Drevneye zhelezo Peredney Azii i nekotoryye problemy arkheologii Volgo-Ural'ya [Ancient iron of Western Asia and some problems of archeology of the Volga-Ural region]. Izvestiya Chelyabinskogo nauchnogo tsentra. V. 1. Chelyabinsk: 73-78. 
14. Dvenadtsat' (12) ornamentov. Analiz mongol'skikh ornamentov [Twelve (12) ornaments. Analysis of Mongolian Ornaments]. URL: https://nadval.livejournal.com/ 39056.html

15. Ivin A. A. (2004). «Filosofiya. Entsiklopedicheskiy slovar'» [«Philosophy. Encyclopedic Dictionary»]. Moscow: Gardariki: 1072. (in Russian)

16. Kubryakova Ye. S. (1997). Kratkiy slovar' kognitivnykh terminov [A Brief Dictionary of Cognitive Terms]. Moscow: Filol. f-t MGU im. M. V. Lomonosova: 245. (in Russian)

17. Leont'yeva V. N. (2003). Kul'turotvorcheskiy protsess: osnovaniya i nachala [Cultural process: foundations and beginnings]. Khar'kov: Konsum: 216. (in Russian)

18. Lippman U. (2004). Obshchestvennoye mneniye [Public opinion] / Per. s angl.T. V.Barchunova, pod red. K. A Levinson, K. V. Petrenko. Moscow: Institut Fonda «Obshchestvennoye mneniye»: 384. (in Russian)

19. Lotman Yu., Uspenskiy B. (1971). O semioticheskom mekhanizme kul'tury [On the semiotic mechanism of culture]. Trudy po znakovym sistemam 5 Uchonyye zapiski Tartuskiy gosudarstvennyy universitet / pod red. Yu. Lotmana. Tartu. V. 284: 144-176.

20. Lotman Yu. M. (1973). Semiotika kino i problemy kinoestetiki [Semiotics of cinema and problems of cinema aesthetics]. Tallin: Eesti Raamat: 92. (in Russian)

21. Lutsiliy Anney Sineka (1977). Nravstvennyye pis'ma k Lutsiliyu. Pis'mo SIV [Moral letters to Lucilius. Letter SYV] / otv. red. M. L. Gasparov, perevod, primechaniye, podgotovka izdaniya S. A. Osherovoy. Moscow: «Nauka». URL: http://ancientrome.ru/antlitr/t.htm? $\mathrm{a}=1346570104$

22. Pirs CH. S. (2000). Izbrannyye filosofskiye proizvedeniya [Selected philosophical works] Moscow: Logos: 448. (in Russian)

23. Popko L. P. (2007). Neologizatsiya v yazyke kak translyatsiya kul'turno-lingvisticheskoy mental'nosti [Neologization in language as a translation of cultural and linguistic mentality]. GARKKiI: 360. (in Russian)

24. Prototip [Prototype]. URL: http://terme.ru/termin/prototip.html

25. Revzin I. I. (1971). Subyektivnaya pozitsiya issledovatelya v semiotike [The subjective position of the researcher in semiotics]. Trudy po znakovym sistemam 5 Uchonyye zapiski / Tartuskiy gosudarstvennyy universitet / pod red. Yu. Lotmana. Tartu. V. S.: 334-344.

26. Stepanov Yu. S. (2004). Konstanty: slovar' russkoy kul'tury [Constants: Dictionary of Russian Culture]. Moscow: Eksmo: 672. (in Russian)

27. Sossyur F. de (2004). Kurs obshchey lingvistiki [General linguistics course]. Moskow: Yeditorial URSS: 256. (in Russian)

28. Uspenskiy B. A. (1971). O semiotike ikony [On the semiotics of icons]. Trudy po znakovym sistemam 5 Uchonyye zapiski. Tartuskiy gosudarstvennyy universitet / pod red. Yu. Lotmana. Tartu. V. 284: 144-166.

29. Fliyer A. Ya. (2016). Simvol v kul'ture: genezis - funktsii - znachimost' [Symbol in culture: genesis - functions - significance]. Observatoriya kul'tury. T. 1. № 1: 94-99. URL: https://observatoria.rsl. ru/jour/article/viewFile/310/15

30. Naime J. S. (2009). Psikhologiya [Psychology]. Belmont: Wadsworth: 565. 